\title{
Numerical simulation of track settlements based on an iterative holistic approach
}

de Miguel, Alejandro; Lau, Albert; Santos, IImar

Published in:

Journal of the Brazilian Society of Mechanical Sciences and Engineering

Link to article, DOI:

10.1007/s40430-018-1300-8

Publication date:

2018

Document Version

Peer reviewed version

Link back to DTU Orbit

Citation (APA):

de Miguel, A., Lau, A., \& Santos, I. (2018). Numerical simulation of track settlements based on an iterative holistic approach. Journal of the Brazilian Society of Mechanical Sciences and Engineering, 40(8), [381]. https://doi.org/10.1007/s40430-018-1300-8

\section{General rights}

Copyright and moral rights for the publications made accessible in the public portal are retained by the authors and/or other copyright owners and it is a condition of accessing publications that users recognise and abide by the legal requirements associated with these rights.

- Users may download and print one copy of any publication from the public portal for the purpose of private study or research.

- You may not further distribute the material or use it for any profit-making activity or commercial gain

- You may freely distribute the URL identifying the publication in the public portal

If you believe that this document breaches copyright please contact us providing details, and we will remove access to the work immediately and investigate your claim. 


\title{
Numerical Simulation of Track Settlements Based on an Iterative Holistic Approach
}

\author{
Alejandro de Miguel · Albert Lau · Ilmar \\ Santos
}

Received: date / Accepted: date

\begin{abstract}
A track settlement algorithm implemented in a multi-body simulation software (MBS) is presented. The purpose is to extend the capabilities of a railway track model so a ballast degradation analysis can be performed. The main idea is to implement a methodology that enables a simulation of the train/track interaction and its influence on the overall track settlement mechanism of a regular track section. For this purpose, the common moving track model widely used in MBS codes is changed to a model in which the track stands still. This is done by inserting, in a discrete way, a set of mass-spring-damper systems along the track. The new way in which the track is modelled allows us, in a more accurate way, to take into account different capabilities of the track model, such as track flexibility and damping conditions, discrete support conditions given by the sleeper distance, and the possibility of modelling each track component independently along the track section. In the novel methodology presented in this work, a settlement algorithm has been directly implemented in the MBS package. The latter makes it possible to simulate the track degradation process given by the settlement of the ballast layer. The process consists of two main phases. In the first one the train/track interaction analysis is carried out. In the second one, the dynamic forces are obtained at the supports along the track, which are then taken and transformed, by applying a settlement law, into vertical displacements that in turn are applied as longitudinal level irregularities in the wheel/rail contact. The process is completed by linking the aforementioned phases in a cyclic mode, considering as many iterations as desired. This work presents an efficient and novel technique that makes MBS code capable of predicting the impact of the accumulated track settlement on the train/track interaction.
\end{abstract}

Keywords Multi-body simulation · Train-track interaction · Ballast settlements

F. Author

Technical University of Denmark Nils Koppels Allé Building 404, room 0142800 Kgs. Lyngby

Tel.: +45 45255622

Fax: +45 45 251961

E-mail: almite@mek.dtu.dk

S. Author

Department of Civil and Environmental Engineering Faculty of Engineering 


\section{Introduction}

The high-level performance requirements and the increasing demand of an efficient railway transport system is evident in many developed countries around the world. Efficiency can be achieved, among other things, by decreasing maintenance and life cycle costs. Theoretical approaches, in particular numerical models, are suitable tools that help the scientific community to reduce reliance on expensive and time-consuming experimental campaigns. From the general scientific trend, one can deduce that most likely, in the coming years, complex numerical track degradation tools will become available to simulate different degradation processes ${ }^{1}$ so the required maintenance works can be properly predicted. This will lead to a significant decrease in the overall costs connected to railway track maintenance operations.

The demanding track geometry specifications (level, alignment, and crosslevel) make the railway system very sensitive to deformations that might significantly affect the train/track interaction. Track settlement is a particular source of track deformation caused when the track is subjected to high vertical and horizontal forces due to train passages. Track maintenance operations are thus needed to retain the track geometry. According to [1] the accumulated track settlement produces fast deterioration that, in turn, can cause progressive plastic deformations and hence further deterioration in track geometry. Track settlement is a phenomenon that is a result of the vertical permanent deformation of one or more layers of the substructure that form the railway infrastructure (ballast, sub-ballast or subgrade), see Fig. 1.

Permanent deformation laws of the subgrade, were studied in [2-6]. More in depth assessments of the sub-ballast layer deformations can be found in $[7,8]$. In this context, the contribution of [9] is particularly remarkable, in which the cyclic evolution (experimental and theoretical) of the vertical permanent strains in the sub-ballast layer is evaluated.

Several authors provide very useful information with regard to the ballast degradation process. Empirical settlement laws for the ballast layer can be found in $[10-15]$. In this layer, degradation can be divided into two main phases [16, 17]. In the first phase the process is rather fast and it is dominated by the consolidation of the ballast layer, mainly due to the rearrangement of the stones. In the second phase, the evolution of the settlements is slower and the relationship between vertical displacements and time is almost linear. Several aspects linked to ballast degradation under cyclic loading are discussed in [18], based on laboratory experiments. In the same work the authors take into account the effect of ballast chipping in the overall degradation process. Other experimental works analyzed the influence of the accelerations on the ballast degradation [19]. In this work, the settlement was found to be a function of the acceleration of sleepers and it was observed that above certain critical values the increase of settlement per cycle was very high. Selig and Waters [20] stated that the ballast layer might be responsible for up to $50 \%-70 \%$ of the total track settlement.

1 as an example, the authors provide the Danish railway national project, INTELLISWITCH, that funded the present work http://www.intelliswitch.dk/ 
Numerical models enable us to predict railway track conditions by increasing track safety and maintenance effectiveness [21], as long as they are properly experimentally validated.

Within numerical simulation tools, the multibody simulation (MBS) approach is an efficient technique to assess the dynamic interaction between the vehicle and the track, particularly at the wheel/rail interface. These MBS codes were originally created to carry out the risk of derailment and passenger comfort assessments. Moreover, MBS software was widely used to simulate the train/track interaction in track regions with complex geometries [22,23]. In the previous works, moving track models were used in the analyses. The main disadvantage of these codes is the inaccurate way of simulating both the track flexibility and the discrete support conditions given by the distance between sleepers. To overcome this limitation, some authors [24] used adapted MBS models in order to properly account for track flexibility and discrete support conditions. The finite element method (FEM) is a different approach; it is very widely used to analyse the interaction between vehicle and track. It provides accurate results when modelling both track flexibility and discrete support conditions. However, computational time using FEM techniques is generally higher than MBS when dynamic interaction assessments are carried out.

Interesting research works have utilized FEM to simulate train/track dynamic interaction. Paixão et al. [25], developed a finite element model to simulate the dynamic effects of a train passing over a transition zone to a railway bridge. In addition to this work, Ribeiro et al. [26] analyzed the positive effect of the under sleeper pads in the train/track dynamic interaction. The track irregularities effect on the interaction forces between track and vehicle was assessed in [27] by means of simplified 2-D and full 3-D FEM models.

In other cases, the scope is to utilize simplified FEM models to carry out stochastic simulations to have a better understanding of the variability of the parameters that characterize the interaction between the train and the track, [28].

As it was pointed out before, computational time is generally the main constraint of the FEM and great efforts have been done to minimize it by improving the contact formulation [29-31]. The efficiency is even lower when track degradation algorithms are directly implemented in FEM codes, as in [32]. To overcome the disadvantages of the FEM when analyzing train/track interaction plus track degradation analyses by using numerical approaches, some authors have used both MBS and FEM methods, as a cross multi-disciplinary procedure, to obtain interaction forces and analyze the effect of soils on the vehicle/track simulations [33, 34]. However, computational efforts when integrating MBS and FEM platforms can still be reduced and this is one of the challenges for railways research in the coming times.

The current paper proposes a new holistic and iterative methodology to simulate railway track settlements by using the commercial MBS software GENSYS ${ }^{\circledR}$, modified and extended by the authors to couple with track compliance. The aforementioned methodology can be used as a tool to check the proper dynamic performance between the track and the vehicle over a long-term period. Capabilities of the tool make it suitable to predict the best time to perform ballast tamping, for a certain track section. 


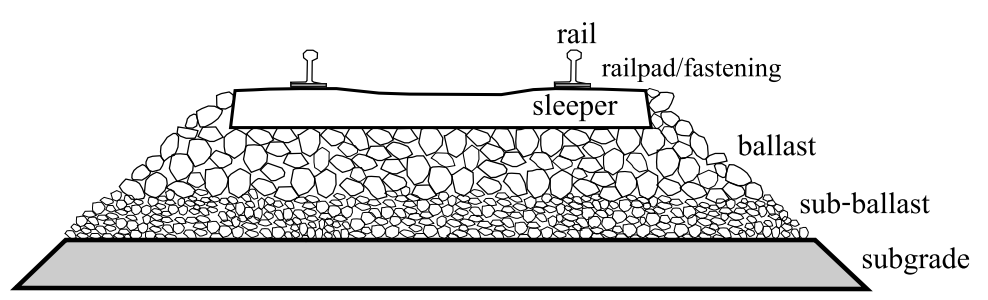

Fig. 1: Main components of a regular ballast track depicted in a cross section

\section{MBS model based on Euler-Bernoulli beam theory and discrete support conditions}

\subsection{Modelling of the rail}

The methodology presented in this section is applied, as an upgrade, of the current model conditions implemented in the commercial MBS software, GENSYS ${ }^{\circledR}$. The reason for that is to overcome the limitations of the moving track models presented in $[22,23]$, in which neither the rail was modelled as a continuous beam nor the discrete support conditions, given by the distance between consecutive sleepers being properly simulated. Moreover, the updated methodology will enable a track degradation analysis to be carried out by implementing a settlement law in the ballast layer.

Here, a fixed track model is created to simulate the dynamic interaction between the moving mass of the train and the track. For this purpose, a continuous multi-span Euler-Bernoulli (EB) beam, elastically constrained at the supports, is modelled. The supports consist of a set of mass-spring-damper systems that simulate the effect of the elements beneath the rail. The sleepers are modelled as lump masses with a constant spacing. Between the lump mass (sleepers) and the EB-beam (rail), a set of spring-damper systems is placed in order to model the railpad. In the same manner, a set of spring-damper systems is placed beneath the sleepers to account for the effect of the ballast layer. The dynamic behaviour of the EB-beam can be characterized by using Lagrange Eq.(1), that is obtained by applying the energy principles of mechanical systems.

$$
L=\frac{1}{2} \mu\left(\frac{\partial y}{\partial t}\right)^{2}-\frac{1}{2} E I\left(\frac{\partial^{2} y}{\partial x^{2}}\right)^{2}+q(x, t) y(x, t)
$$

where $\mu$ refers to the mass per unit length, $E$ is the elastic modulus and $I$ is the second moment of area of the beam's cross-section. In Eq.(1) the first term represents the kinetic energy; the second one represents the potential energy due to internal forces and the third one stands for the potential energy due to the external load $q(x, t)$. By applying modal superposition, the vertical deflection of the beam $y(x, t)$ is expressed below, given by a linear combination of its first $h$ undamped mode shapes.

$$
y(x, t)=\sum_{i=1}^{h} \phi_{i, x} W_{i}(t)
$$


where $\phi_{i, x}$ and $W_{i}(t)$ denote the $i$ mode-shape vector and the modal coefficient of the vertical deflection $y(x, t)$, respectively. By substituting Eq.(2) into the energetic expression given by Lagrange equation, a set of $i$ ordinary differential equations are obtained. Each equation describes a single degree of freedom model, in the considered modal subspace. Rayleigh viscous damping conditions are taken into account to get the proportional damping coefficient. The set of differential equations Eq.(3) can be solved, in a quite efficient way, by using numerical integration techniques.

$$
\ddot{W}_{i}+2 \xi_{i} \omega_{i} \dot{W}_{i}+\omega_{i}^{2} W_{i}=\frac{q}{m_{i}}
$$

where $m_{i}, \xi_{i}$ and $\omega$ refer to the modal mass, damping ratio and modal frequency of the $i^{t h}$ mode respectively. The parameter $q$ refers to the external load vector acting on the system.

When defining the beam in the MBS Code, GENSYS ${ }^{\circledR}$, the Euler-Bernoulli beam function is a massless beam and the beam mass can only be taken into account by adding masses that are rigidly connected under the beam so the EulerLagrange, Eq.(1), is only completed when the masses of the rail are defined under the beam. The masses are rigidly constrained in all directions except for the vertical translation and rotation in the pitch direction. The beam can act like a coupler that allows more masses such as sleeper masses, ballast masses, etc. to be connected underneath, in order to represent a more complex track geometry, see Fig. 2a and Fig. 2b. The nomenclature for each element used in the track modelling can be seen in Table 1.

For a multi-span continuous beam, beam elements are utilized to properly represent the bending stiffness of the rail at each track section. The sleepers are modelled as rigid mass bodies, and the mass elements used to simulate the sleepers are constrained in a similar way as for the rail masses. It is worth noting that the presented model is able to consider both the stiffness of the rail and the mass of the sleeper as dependent variables along the track in the longitudinal direction. Thanks to this, it is possible to model complex track geometries in which the geometric and mechanical properties are not constant along the longitudinal direction of the track such as the rail profiles in switches and crossings.

\subsection{Static and dynamic theoretical validations of the track model}

New implementations in the model should be validated to check the suitability of the new model. For this purpose, the authors decided to validate the model statically and dynamically, against a more sophisticated FEM model described in [26]. A similar validation technique can be found in [27] in which 2-D FEM models were benchmarked against more complex 3-D FEM models. To achieve the aforementioned goal, a regular stretch of track is created for both MBS code, where the Euler-Bernoulli (EB) conditions previously described have been considered, and the 2-D FEM package that has been used as a benchmark in this work. The main track components considered in the validation process are the rail, the railpad, the sleepers and the ballast layer. The MBS based on the EB conditions consists of a Euler-Bernoulli beam that can be discretized into smaller beam elements. This beam aims at simulating the effect of the rail, which is elastically supported on the 


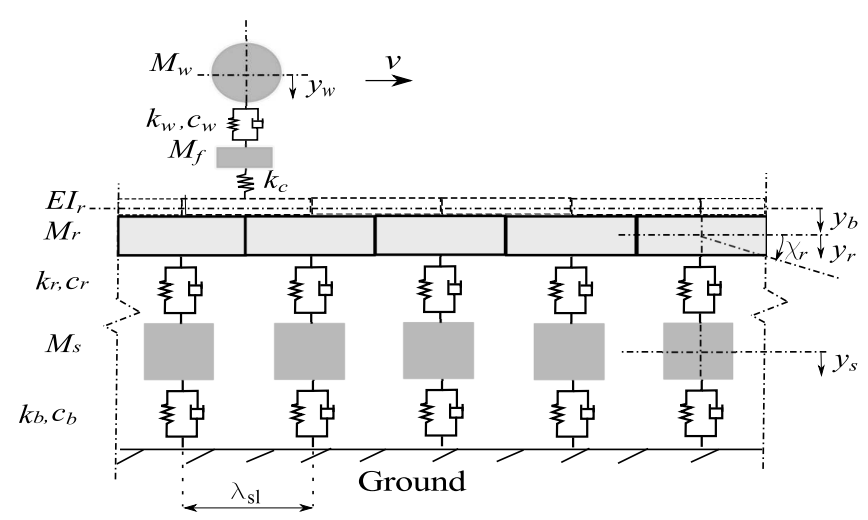

(a)

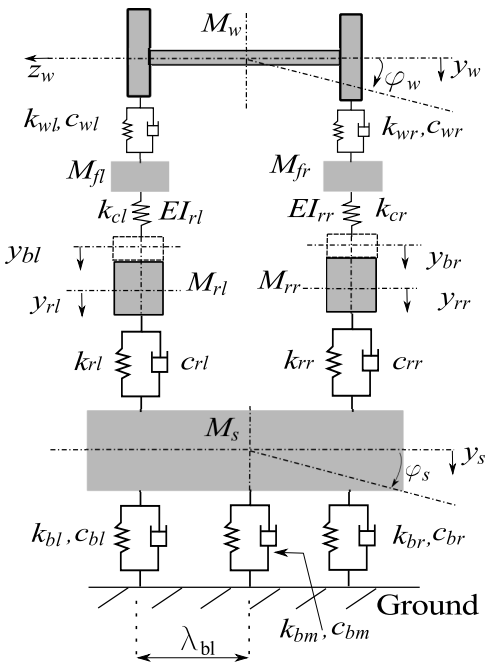

(b)

Fig. 2: Layout of the discretized track model created in the GENSYS ${ }^{\circledR}$ MBS software; (a) side view; (b) front view.

elastic railpads underneath. A set of masses evenly distributed aims at simulating the mass of the sleepers. Finally, the model is completed by modelling the ballast layer in a similar way as the railpads by elastically connecting the sleeper masses to the subgrade which, in this particular case, is considered to be infinitely rigid.

An equivalent FEM model is created in the commercial sofware ANSYS ${ }^{\circledR}$. Similar models were previously used in $[26,35]$ and validated both statically and dynamically. The equivalent FEM model consists of a two-dimensional approach where the rails are modelled using discrete beam elements (BEAM3). The railpads are modelled using spring-damper systems (COMBIN14). Sleepers and ballast layer are in this case modelled by means of plane stress finite elements (PLANE182). A layout of each model is shown in Fig. 3. The type of element and the mechanical 
Table 1: Nomenclature of mechanical parameters of Fig. 2.

\begin{tabular}{|c|c|}
\hline \multicolumn{2}{|c|}{ Notations } \\
\hline$v$ - wheelset velocity & $k_{b r}-$ ballast stiffness (right) \\
\hline$M_{w}$ - wheelset mass & $c_{b l}$ - ballast damping (left) \\
\hline$M_{r l}-$ left rail mass & $c_{b m}$ - ballast damping (middle) \\
\hline$M_{r r}$ - right rail mass & $c_{r r}$ - railpad damping (right) \\
\hline$M_{s}$ - sleeper mass & $y_{w}$ - wheelset vertical displacement \\
\hline$M_{f}$ - fictitious rail mass & $z_{w}$ - wheelset lateral displacement \\
\hline$k_{w}$ - wheel-rail contact stiffness & $\varphi_{w}$ - wheelset roll rotation \\
\hline$c_{w}$ - wheel-rail contact damper & $y_{b l}$ - left rail vertical displacement \\
\hline$k_{c}$ - rail-rail contact stiffness & $y_{b r}$ - right rail vertical displacement \\
\hline$E I_{r l}-$ left rail bending stiffness & $y_{r l}-$ left rail mass vertical displacement \\
\hline$E I_{r r}$ - right rail bending stiffness & $y_{r r}$ - right rail mass vertical displacement \\
\hline$k_{r l}$ - left railpad stiffness & $\chi_{r l}-$ left rail mass pitch rotation \\
\hline$k_{r r}$ - right railpad stiffness & $\chi_{r r}$ - right rail mass pitch rotation \\
\hline$c_{r l}-$ left railpad damping & $y_{s}$ - sleeper mass vertical displacement \\
\hline$c_{r r}$ - right railpad damping & $\varphi_{s}-$ sleeper mass roll rotation \\
\hline$k_{b l}-$ left ballast stiffness & $\lambda_{s l}-$ sleeper distance \\
\hline$k_{b m}$ - right railpad damping & $\lambda_{b l}$ - ballast supports distance \\
\hline
\end{tabular}

Euler-Bernoulli beam (Rail)

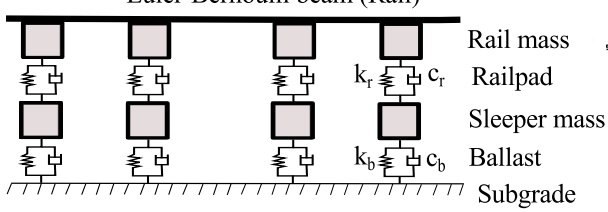

(a)

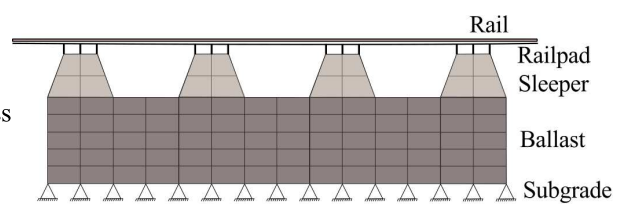

(b)

Fig. 3: Layouts of the two track models. (a) MBS model; (b) FEM model

parameters used for both the MBS and the FEM models are depicted in Tables 2 and 3 , respectively.

Table 2: Elements used in the MBS and FEM codes to model the track components

\begin{tabular}{|c|c|c|c|c|}
\hline $\begin{array}{l}\text { Track } \\
\text { compo- } \\
\text { nents }\end{array}$ & $\begin{array}{l}\text { Elements } \\
\text { MBS model }\end{array}$ & $\begin{array}{l}\text { Elements } \\
\text { FEM model }\end{array}$ & $\begin{array}{l}\text { Nomenclature } \\
\text { Elements } \\
\text { MBS model }\end{array}$ & $\begin{array}{l}\text { Nomenclature } \\
\text { Elements } \\
\text { FEM model }\end{array}$ \\
\hline Rail & Beam & Beam & Beam_3 & BEAM3 \\
\hline Railpad & Spring-damper & Spring-damper & Plin_36 & COMBIN14 \\
\hline Sleeper & Mass & $\begin{array}{l}2-\mathrm{D} \\
\text { stress }\end{array}$ & M_rigid_6f & PLANE182 \\
\hline Ballast & Spring-damper & $\begin{array}{l}2 \text {-D } \\
\text { stress }\end{array}$ & Plin_36 & PLANE182 \\
\hline
\end{tabular}

The validation of the MBS model is fundamental to check the suitability of the program. In this context, it is worth noting that the commercial code GENSYS ${ }^{\circledR}$, used in this work, was previously benchmarked against other MBS codes [36]. The validation successfully proved that the MBS code is suitable to detect the interaction forces acting on the wheel/rail interface in track regions characterized by complex geometries such as railway turnouts. In this particular case, a 
Table 3: Track parameters used in the simulation. Assumed values taken from reference magnitudes [27,39].

\begin{tabular}{ll}
\hline Parameter & Value \\
\hline Model length $(\mathrm{m})$ & 30 \\
Beam discretization $(\mathrm{m})$ & 0.01 \\
Sleeper spacing $(\mathrm{m})$ & 0.60 \\
Rail bending stiffness $\left(\mathrm{Nm}^{2}\right)$ & $6.11 \times 10^{6}$ \\
Rail mass $(\mathrm{kg} / \mathrm{m})$ & 60 \\
Railpad stiffness $(\mathrm{N} / \mathrm{m})$ & $200 \times 10^{6}$ \\
Railpad damping $(\mathrm{Ns} / \mathrm{m})$ & $30 \times 10^{3}$ \\
Half Sleeper mass $(\mathrm{kg})$ & 157.4 \\
Ballast stiffness $(\mathrm{N} / \mathrm{m})$ & $160 \times 10^{6}$ \\
Ballast damping $(\mathrm{Ns} / \mathrm{m})$ & $500 \times 10^{3}$ \\
Ballast thickness $(\mathrm{m})$ & 0.40
\end{tabular}

simplified moving track model was used to carry out the validation. The simplified model provides a rough indication of where in the turnout the maximum peaks of contact forces occur. This together with the short computational time, makes the software valid for optimization analyses of the track geometry or for probabilistic/risk assessments where a large quantity of simulations are required to simulate the development of the forces (or degradation of the ballast) over time or number of cycles. However, the current modelling approach which is based on a moving track model presents two drawbacks. The magnitude of contact forces is not accurately obtained because of the simplifications assumed in the way of modelling the track, since the latter does not stand still. As a consequence of the moving track approach, the track flexibility conditions and the discrete support effect given by the sleeper distance are not properly simulated. The second drawback refers to the constraints given by the oversimplified outputs of the moving track model, since it can only provide time history results of different variables (accelerations, velocities, displacements and forces) at different vehicle components but not for any of the track components.

A standing still track model is fundamental when a degradation analysis is performed because it takes into account the continuity within the model and so, longitudinal level irregularities can be simulated when a degradation law (permanent settlements) is introduced at different layers within model. Thus, it is very important to carry out a validation of the MBS model to be sure that the model is able to characterize the track behaviour under static and dynamic loading conditions. Through a static validation, the static displacement is obtained when a vertical point load is applied on the top of the rail, so the proper configuration of the mass-spring-damper system underneath the rail can be verified, see Fig.4a. The purpose of the dynamic validation is to dynamically characterize the track system, so the proper configuration of the mass-spring-damper elements attached to the EB beam elements can provide information about the main resonant frequencies and mode shapes of the track system, as referred in [37]. The purpose of this test is to derive the receptance curve of the track by applying a harmonic load in the middle span between two sleepers. Track receptance function, as well as the mobility function, is a way of deriving the dynamic flexibility of the track [38]. The relationship between the displacement and the force provides such a function, see Fig.4b. 


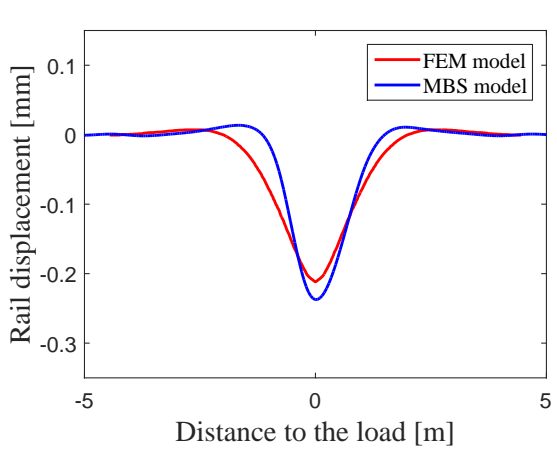

(a)

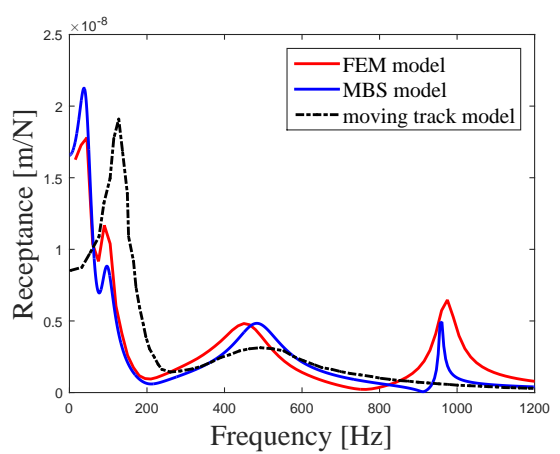

(b)

Fig. 4: Validation of the MBS model taking as a reference the FEM model; (a) static validation; (b) dynamic validation.

\subsection{Validation of the train/track interaction}

Once the static and dynamic validations of the track have been completed, it is also necessary to validate the track model when it is coupled with a vehicle model. This validation intends to verify that a proper train/track interaction is obtained when the vehicle is moving over the track. For this reason, a simplified model of a train wheelset is created for both the MBS and the FEM models. In this case, the wheelset runs along a regular stretch of track with a total length of $30 \mathrm{~m}$, as described in the previous section. To simplify the analysis, only the rail and the flexibility provided by the railpads will be considered. The dynamic interaction response obtained in this analysis may be used to prove that the MBS model based on the Euler-Bernoulli beam theory and discrete support conditions, previously described, is able to capture some of the main resonant frequencies involved in the train/track interaction phenomenon. The main characteristics of the wheels/track coupling are depicted in Fig.5c.

Mechanical characteristics used to perform the dynamic interaction between the wheelset and the track are listed below in Table 4 .

Through the analysis of the dynamic interaction forces, in the frequency domain, the main resonant frequencies can be detected in the MBS model. Figure 6a shows three peaks obtained at $36 \mathrm{~Hz}, 67 \mathrm{~Hz}$ and $74 \mathrm{~Hz}$. The sleeper passing frequency is obtained by dividing the speed of the wheelsets by the distance between sleepers. So in this case, the sleeper passing frequency is $37.03 \mathrm{~Hz}$ (the second harmonic lies around $74 \mathrm{~Hz}$ ). The second peak corresponds to a transient behaviour of the wheelset/interaction, which has a big influence on the initial phase of the contact force. This frequency corresponds to a transient interval in which the vehicle comes into the track model and both systems bounce up and down together. A modal analysis which is carried out in ANSYS ${ }^{\circledR}$ provides a frequency for the aforementioned bouncing vibration mode of $66.60 \mathrm{~Hz}$.

Note that for the case in which the interaction forces, coming from the moving track are analysed, none of these peaks are captured (black line) in Fig.6a. This implies a substantial improvement of the response given by the unmodified models 


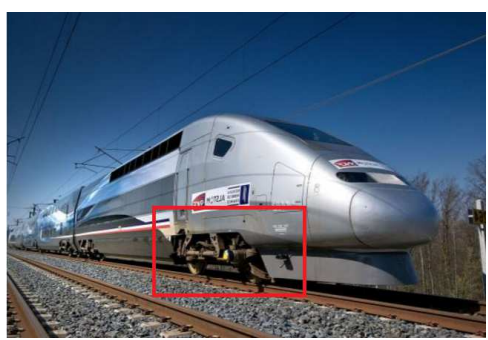

(a)

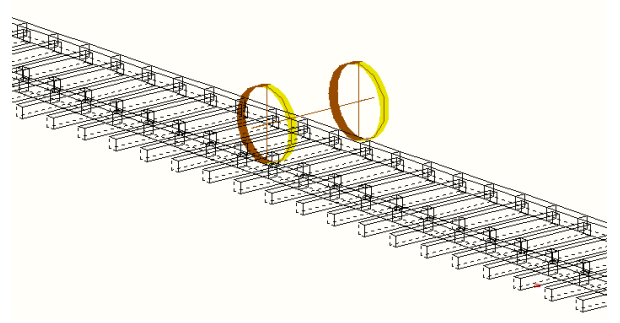

(b)

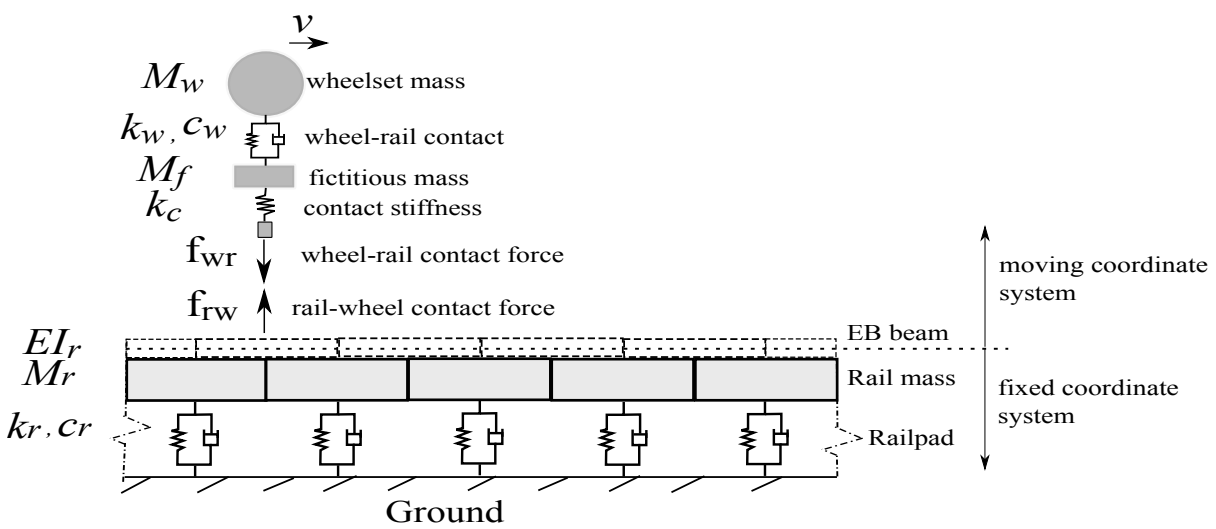

(c)

Fig. 5: Wheelset/track interaction; (a) Photo taken from rail magazine website; (b) graphical layout in GENSYS ${ }^{\circledR}$; (c) main MBS elements.

used by the MBS software to analyse dynamic interaction between the vehicle and the track. It should be noted that although the computational time increases for the newly modified MBS model, based on the EB-beam conditions, the computational efficiency still remains within tolerable limits, especially when compared with the efficiency provided by the more complex FEM methodologies. This makes the improved MBS model more suitable to perform tedious degradation simulations.

\section{Description of the implemented degradation process}

\subsection{Empirical laws of track degradation}

According to [20], the contribution of the ballast layer settlement may represent up to $70 \%$ of the overall settlement of the track, see Fig.6b. For this reason, the ballast layer is one of the track components with the highest influence on the overall track degradation process, which is why in many cases, research works focus 
Table 4: Main parameters used in the simulation of the wheelset/track dynamic interaction. Assumed values taken from reference magnitudes $[27,39]$.

\begin{tabular}{ll}
\hline Parameter & Value \\
\hline Model length $(\mathrm{m})$ & 30 \\
Beam discretization $(\mathrm{m})$ & 0.01 \\
Railpad spacing $(\mathrm{m})$ & 0.60 \\
EB bending stiffness $\left(\mathrm{Nm}^{2}\right)$ & $6.11 \times 10^{6}$ \\
Rail mass $(\mathrm{kg} / \mathrm{m})$ & 60 \\
Railpad stiffness $(\mathrm{N} / \mathrm{m})$ & $200 \times 10^{6}$ \\
Railpad damping $(\mathrm{Ns} / \mathrm{m})$ & $30 \times 10^{3}$ \\
Wheelset speed $(\mathrm{km} / \mathrm{h})$ & 80 \\
Wheelset mass $(\mathrm{kg})$ & 1800 \\
Wheel/rail contact stiffness & $600 \times 10^{6}$ \\
$(\mathrm{~N} / \mathrm{m})$ & \\
Wheel/rail damping coefficient & $600 \times 10^{3}$ \\
$(\mathrm{Ns} / \mathrm{m})$ & \\
Contact stiffness $(\mathrm{N} / \mathrm{m})$ & $1.43 \times 10^{9}$
\end{tabular}

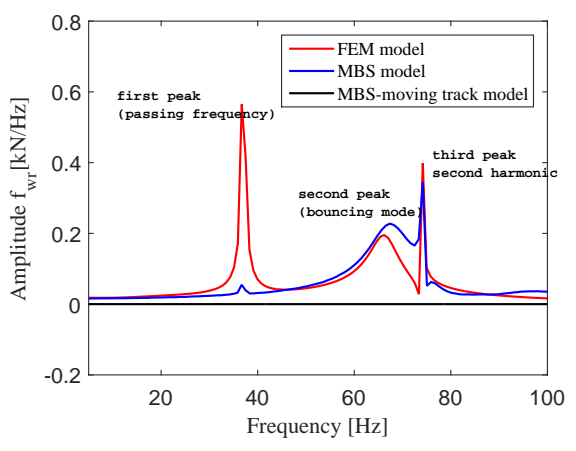

(a)

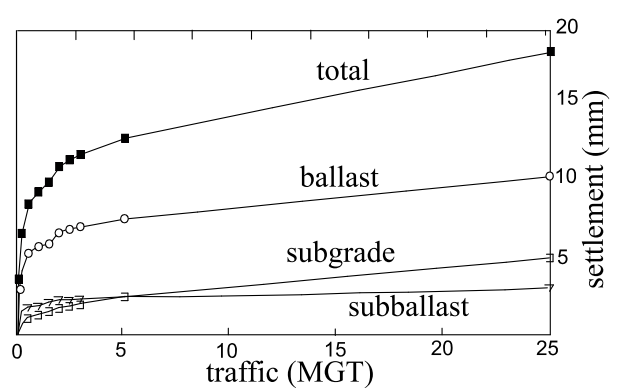

(b)

Fig. 6: (a) Interaction forces amplitude in frequency domain for the FEM, MBS and moving track models; (b) Contribution of different layers to the total track settlement, adapted from [20].

on predicting track settlement evolution by only taking into account permanent deformations of the ballast layer.

The settlement of the ballast layer can be due to settlements of the layers beneath it such as the subballast or the subgrade. It can be also due to the rearrangement of its stones or due to the wear of the ballast stones causing a rounding of the stones.

Wear and degradation phenomena can be easily distinguished by analysing small variations in the height of the ballast layer.

The existing degradation laws that have been used to evaluate the deformation of the ballast layer, have worked either by predicting the permanent deformation of the materials that form this layer or through a direct prediction of the whole layer deformation. These are described in this section. 
In this respect, [20] came up with different degradation laws based on experimental campaigns. The authors suggested the empirical law given by Eq.(4) to describe permanent ballast settlements.

$$
\varepsilon_{N}=\varepsilon_{1} N^{\beta}
$$

where $\varepsilon_{1}$ refers to the permanent deformation obtained during the first loading cycle, $\beta$ is a constant and $N$ is the number of cycles. According to the experimental data obtained by Selig and Waters in [20], $\varepsilon_{1}$ and $\beta$ take the values of $0.35 \%$ and 0.21 , respectively.

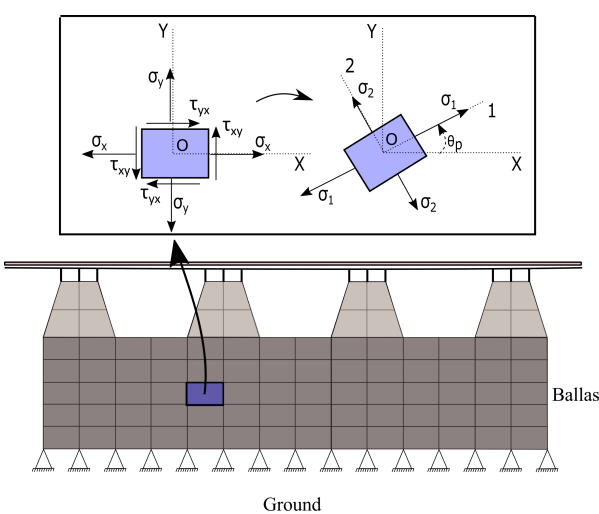

(a)

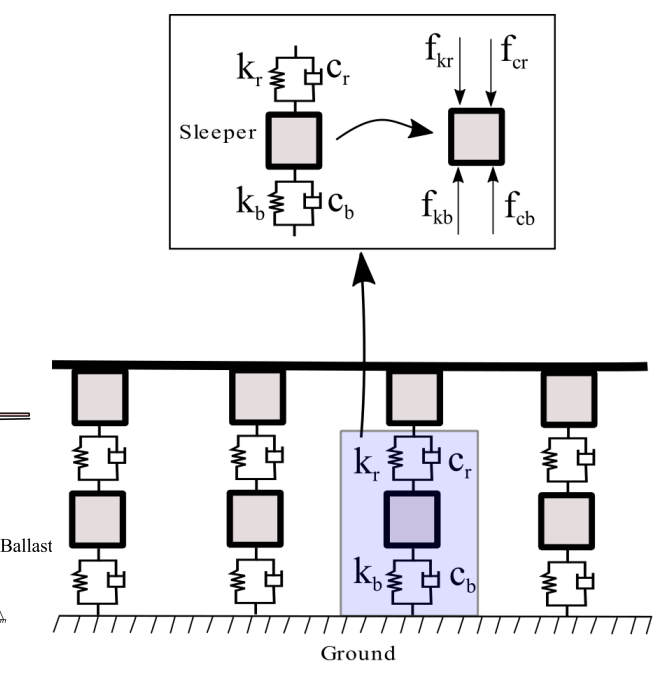

(b)

Fig. 7: Stress/force status at the ballast layer (a) Deviatoric stress;(b) Reaction force in the sleeper.

It has been concluded that the growth rate of the permanent track settlement is significantly reduced as the number of loading cycles increases [10]. In the latter work, it was verified that the first loading cycle causes a very high deformation of the ballast layer. Afterwards the permanent settlement law, corresponding to this layer, follows a logarithmic function like the one given in Eq.(5).

$$
\varepsilon_{N}=\varepsilon_{1} N(1+C \log (N))
$$

where $\varepsilon_{N}$ refers to the permanent deformation of the ballast layer after $N$ loading cycles, $C$ is a constant that, according to [10], is equal to 0.20 and $\varepsilon_{1}$ refers to the permanent deformation given by the first loading cycle, see Eq.(6):

$$
\varepsilon_{1}=0.082\left(100 n_{p}-38.2\right)\left(\sigma_{1}-\sigma_{2}\right)^{2}
$$

where $\left(\sigma_{1}-\sigma_{2}\right)$ is the deviatoric stress magnitude (given by the difference between the major and minor principal stresses) acting in the ballast layer, see Fig. 7a. 
Parameter $n_{p}$ refers to the porosity of the ballast layer that, in turn, depends on both the initial tamping level and the mechanical characteristics of the ballast layer. The latter parameter usually varies between 0.40 and 0.50 , according to [20]. In order to implement this law into a numerical model, it is necessary to carry out an assessment of the deviatoric stress level at the ballast layer. This characteristic makes the empirical degradation law that has been utilized perfect for numerical methodologies that are able to directly provide stress as outputs of the model, such as FEM packages. Unlike the FEM packages, the MBS packages, such as GENSYS, only outputs the forces. It is not straightforward to implement such a law in the improved version of the MBS, as described in the previous section. For this reason, it is necessary to implement a similar law that is described by means of forces instead of stresses. Such a degradation law was described by [11]. It is similar to that defined in Eq.(5) and it fits perfectly into the capabilities of the MBS model, because, unlike Eq.(5), the ballast settlement is given as a function of the reaction force in the sleepers, see Fig. $7 \mathrm{~b}$. The magnitude of the reaction force in the sleeper can directly be obtained as an output from the proposed MBS model. The empirical settlement law used in the MBS model is expressed by Eq.(7).

$$
u_{N}=u_{1}(1+C \log (N))
$$

where $u_{N}$ is the permanent settlement of the ballast layer after $N$ loading cycles. $C$ is a constant that, according to $[11,40]$ is equal to 0.43 . The settlement during the first loading cycle, $u_{1}$, depends on the magnitude of the reaction force in the sleeper, $F$ and the parameters $s$ and $a$, as well. See Eq.(8).

$$
u_{1}=s F^{a}
$$

where the parameter $s$ might take a constant value of $0.00095 \mathrm{~mm} / \mathrm{kN}$, [40] or a variable value $0.001 \mathrm{~mm} / \mathrm{kN}-0.0004 \mathrm{~mm} / \mathrm{kN}$ depending on the conditions of the track foundation, [11].

\subsection{Iterative process to simulate track settlements in the MBS code}

Prediction of railway track settlement is done in this work by implementing an iterative process like the one depicted in Fig.8. To achieve this, two different packages are integrated into a single tool that is able to predict the degradation of the track, in terms of ballast settlement, during each iteration analysis. The first package is the MBS model described in Section 2, which is created using the multibody simulation software GENSYS ${ }^{\circledR}$. The second package is written in a program developed in the scientific program language OCTAVE ${ }^{\circledR}$, which contains the algorithm that calculates and applies the track settlement magnitude using Eq.(7) and Eq.(8).

In the first phase, the vehicle/track interaction using the MBS model is simulated in GENSYS ${ }^{\circledR}$. The train passage generates dynamic forces in all the springdamper systems located underneath the rail and along the stretch of track. Afterwards, the dynamic forces acting on the elements (springs and dampers) that converge into the sleepers mass are conveniently stored. At each time step the forces coming from (see Fig.7b) the ballast spring $f_{k b}$, ballast damper $f_{c b}$, railpad 
STARTING POINT: number of iterations=i

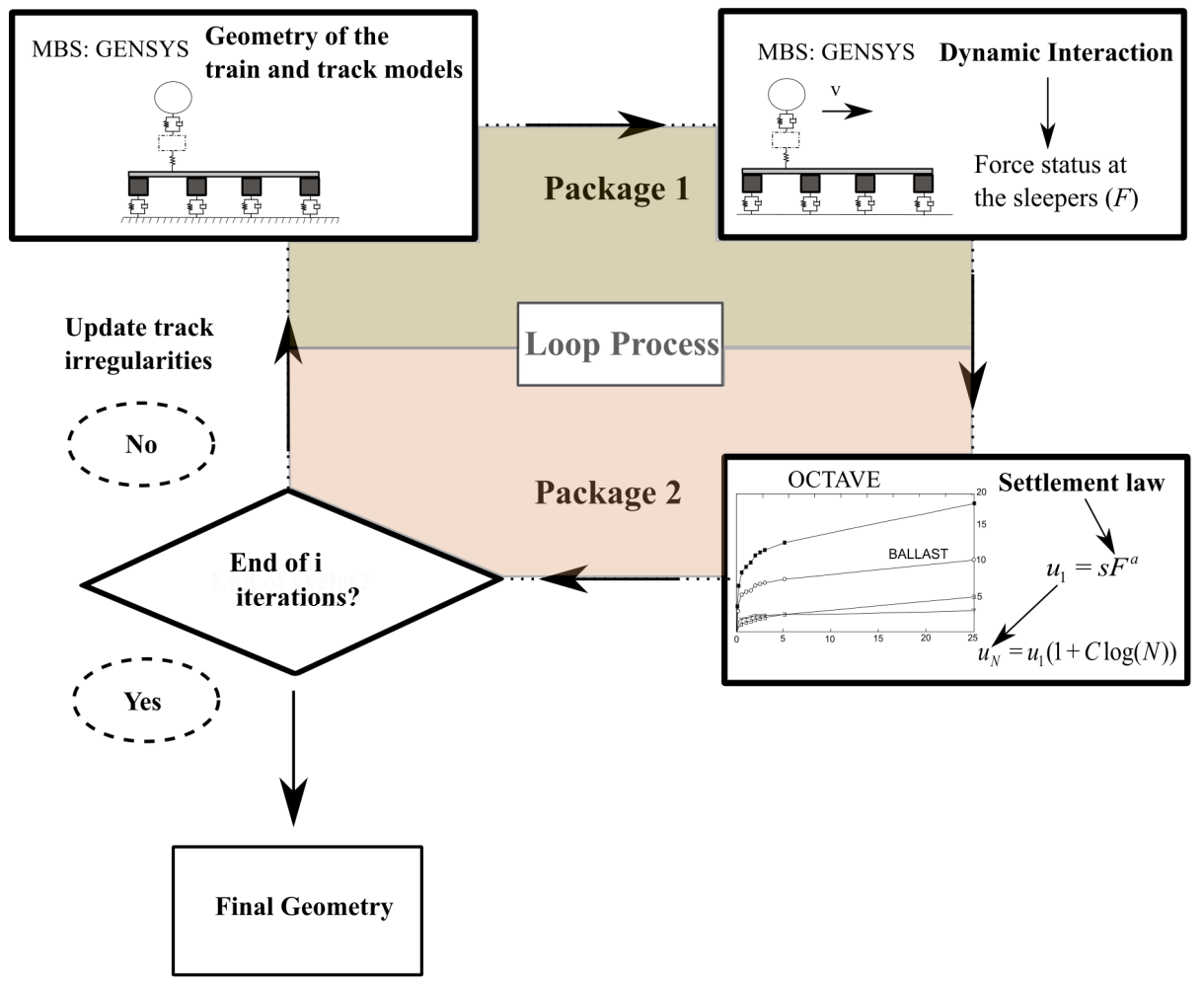

Fig. 8: Flow chart for the iterative process to predict track settlements by means of an MBS code.

spring $f_{k r}$ and railpad damper $f_{c r}$ are added and the maximum of the resulting force (pointing downward) over the time history is conveniently stored. The process is repeated for each sleeper of the model so a vector that contains the magnitude of the resulting forces, previously obtained, at each sleeper of the model is obtained. The dynamic interaction analysis is done via an implicit solver with a constant time step of 0.0001 seconds.

In a second phase, the forces are used to calculate the ballast settlement during the first loading cycle using Eq.(8) and the permanent settlement (in the vertical direction) of the ballast layer after $N$ cycles, Eq.(7). The magnitude of the permanent settlement caused by a single train passage is too low. Thus, the degradation analysis will be carried out considering a set of $\Delta N$ cycles, instead of only one at each iteration.

The values of ballast settlement (vertical displacements), obtained in OCTAVE ${ }^{\circledR}$ are introduced back into the MBS model, as longitudinal level track irregularities in the rail. These irregularities are fed back into the MBS program as vertical displacements experienced by the wheelsets along the track. The vertical displacements are written as 2 columns vector form where the first column is the wheel position and the second columns refers to the displacement of the wheel. 
Once the geometry of the track has been updated, a new dynamic calculation between the train and the track is carried out in the improved MBS model, so the loop process to calculate track settlements can be repeated as many times as necessary. The stopping criterion is defined in the beginning of the iterative process by defining the number of total iterations $i$, see Fig. 8 The following assumptions have been made to perform the track degradation assessment:

- Only vertical settlements of the track are considered.

- For each $\Delta N$ (loading cycle) the forces and track geometry remain constant.

- Irregularities, at each iteration, are considered for both rails and they have the same magnitude. The magnitude of the irregularity is taken as a result of the average of the displacements coming from the forces acting on both the left rail and the right rail.

\subsection{Solution adopted to avoid settlement discontinuities}

The force status is supposed to be constant for each increment. However, at the end of each set of $\Delta N$, the force status is evaluated and utilized in Eq.(7) and Eq.(8) to obtain a new settlement law. This means that at each $\Delta N$ one would obtain two different magnitudes of settlement corresponding either to the new force status or to the previous one. To overcome this boundary problem, [11] suggested shifting the settlement curves corresponding to different force status, see Fig.9.

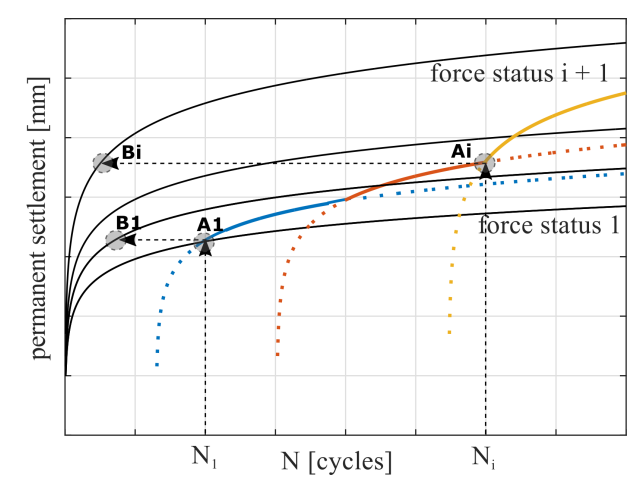

Fig. 9: Transition of settlement laws by curve shifting

According to Fig.9, up to $N 1$, the settlement law for force status 1 is taken into account. From $N 1$, settlements are given by the curve that corresponds to force status 2 . At this point, it is necessary to identify the settlement magnitude at the curve obtained for the first force status, point $A 1$, and for the second force status, point $B 1$. Distance $A 1-B 1$ will be the shifting value to the right for the whole settlement curve corresponding to the second force status. This shifting process will be carried out at every $\Delta N$ until the degradation analysis is completed. 
4 Numerical results of the settlement algorithm

With the purpose of testing the described methodology, in which a degradation law is implemented into the improved MBS model, a simplified train/track interaction example is assessed. For this particular case, the track model and the vehicle model are the same as those described in Section 2. The speed of the wheelset is for this case $80 \mathrm{~km} / \mathrm{h}$. It is possible to evaluate the increase of contact forces when a change of stiffness in the ballast layer is considered. This stiffness variation will generate an uneven distribution of contact forces around the stiffness transition point. Different force magnitudes at the sleepers around the transition will generate different settlement rates at each sleeper. Settlement rate is more accelerated in the vicinities of the transition, which in turn causes increased differential settlements and irregularities around the location in which the ballast stiffness has changed.

Results coming from two different scenarios are presented. In the first scenario it is assumed that there are no changes in the ballast stiffness along the entire length of the track model. For the second scenario, the ballast stiffness is increased $10 \%$ at sleeper 40 , located $24 \mathrm{~m}$ from the beginning of the model. For both scenarios a total of 6 iterations have been carried out in the program. Each iteration corresponds to 50000 train passages. So according to Fig. $9, N=50000$.

In Fig.10, results for the first scenario (no ballast stiffness variation) are depicted. The permanent track deformation or settlement shown in Fig.10a presents a homogeneous distribution along the model and this is reflected in negligible variations of the magnitude of the contact forces in Fig.10b.

On the other hand, when an initial increment of the ballast stiffness is assumed, the pattern for both track settlements and contact forces, Fig.11a and Fig.11b, respectively, presents a remarkable increment around the location in which the ballast stiffness transition takes place. This result proves that the model is able to simulate singular defects or irregularities along the track due to the particular way of modelling the different track components by means of discrete support mass-spring-damper systems. The iterative loop implemented to simulate the track degradation phenomenon provides the evolution of the longitudinal level track irregularities. 


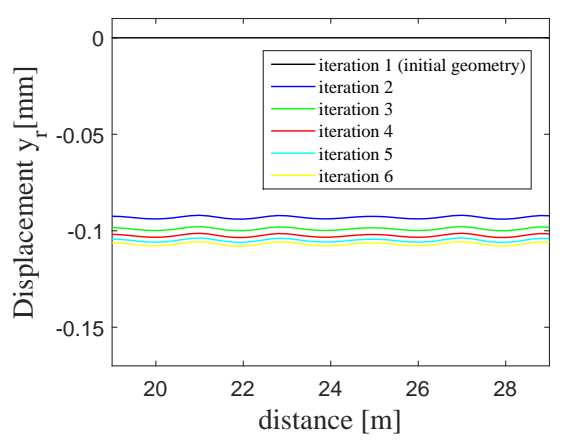

(a)

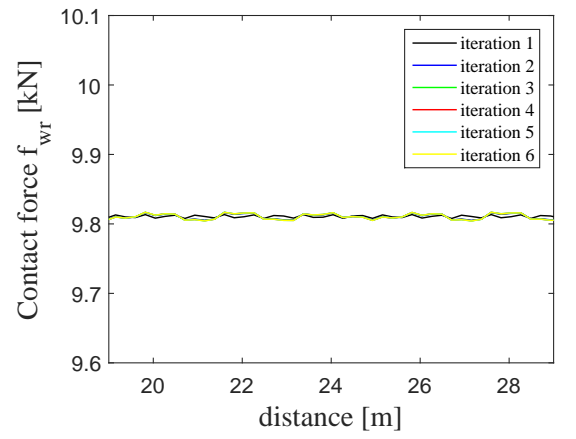

(b)

Fig. 10: Track settlement simulation for an even ballast stiffness (a) vertical displacements of the rail; (b) Wheel/rail interaction force.

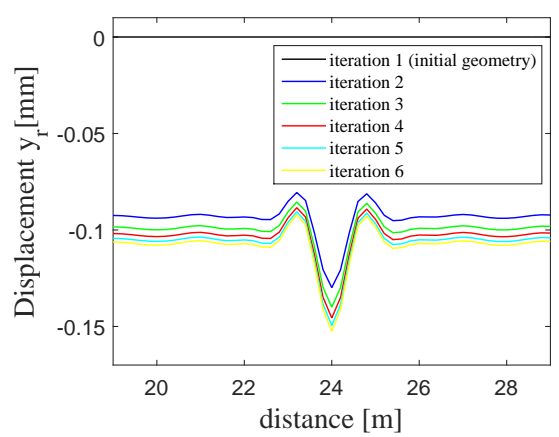

(a)

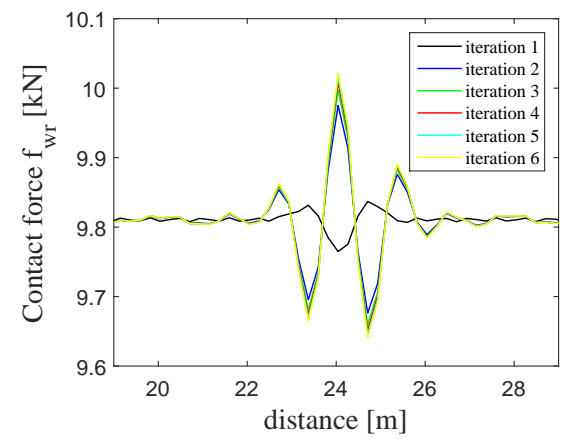

(b)

Fig. 11: Track settlement simulation for an uneven ballast stiffness (24m) (a) vertical displacements of the rail; (b) Wheel/rail interaction force.

\section{Conclusions}

An evaluative ballast settlement algorithm has been implemented into the modified commercial MBS code GENSYS ${ }^{\circledR}$, so the program is able to carry out long-term simulation analyses to assess the evolution of both the dynamic interaction forces between the vehicle and the track and the longitudinal level track irregularities. The whole settlement procedure can be analyzed by considering as many cycles as is desired by running a numerical loop process. The main advantage of this procedure is the low computational time compared to FEM methodologies. This methodology applied for a regular track section, can be extended to other track critical regions, such as railway turnouts or transition zones where track degradation is an accelerated process mainly due to the large magnitude of contact forces acting between the train and the track. MBS codes and particularly the improved 
MBS model presented in this work, have proven to be a capable methodology to evaluate track settlements. It provides results of the train/track interaction, which is then fed back into the track settlement algorithm that generates an updated track geometry at each iteration. Furthermore, the implemented settlement algorithm allows one to include a large variety of settlement laws that better fit the requirements of the user.

A systematic track measurement campaign would be necessary to calibrate and validate the numerical model and the methodology proposed in this work. Furthermore, it is necessary to implement the described methodology into a numerical model that describes special track regions where impact forces and consequently track geometry variations are really hard obtain, such as railway turnouts or transition zones.

\section{References}

1. Kennedy J., Woodward P. K., Medero G., and Banimahd M.: Reducing railway track settlement using three-dimensional polyurethane polymer reinforcement of the ballast. Construction and Building Materials, 44, 615-625 (2013).

2. Puppala A. J., Mohammad L. N., and Allen A.: Permanent deformation characterization of subgrade soils from RLT test. Journal of Materials in Civil Engineering, 11(4), 274-282 (1999)

3. Li D. and Selig E. T.: Method for railroad track foundation design. I: Development. Journal of Geotechnical and Geoenvironmental Engineering, 124(4), 316-322 (1998).

4. Ge-xu J. I. A. and Xian-jing K. O. N. G.: Study on residual deformation characteristics of coarse-grained soils [J]. Chinese Journal of Geotechnical Engineering, 1, 004 (2004).

5. Li D. and Selig E. T.: Evaluation of railway subgrade problems. Transportation Research Record, 1489, 17 (1995).

6. Tan Q. L. and Xie C.: Comparison and analysis of permafrost railway subgrade settlement deformation monitoring. In Applied Mechanics and Materials (Vol. 226, pp. 1651-1654). Trans Tech Publications (2012).

7. Ribeiro, A. C. C. A.: Transições aterro-estrutura em linhas ferrovirias de alta velocidade: análise experimental e numérica., Ph.D thesis, Technical University of Porto (2012).

8. Ferreira T., Teixeira P. F. and Cardoso R.: Effects of incorporating a bituminous subballast layer on the deformation of railway trackbeds. In Bearing Capacity of Roads, Railways and Airfields. 8th International Conference (BCR2A'09) (2009).

9. Suiker A. S. and de Borst R.: A numerical model for the cyclic deterioration of railway tracks. International journal for numerical methods in engineering, 57(4), 441-470 (2003).

10. Ford R.: Differential ballast settlement, and consequent undulations in track, caused by vehicle-track interaction. Vehicle System Dynamics, 24(sup1), 222-233 (1995).

11. Hunt H. E. M.: Track settlement adjacent to bridge In: Vehicle-Infrastructure Interaction IV, San Diego, USA. (1996).

12. Shenton M. J.: Ballast deformation and track deterioration. In Track technology (pp. 253-265). Thomas Telford Publishing (1985).

13. Ishida M., Namura A. and Suzuki T.: Track dynamic analysis for track settlement and irregularity growth. In proceedings of the international conference of railway engineering, London, UK, July (2002).

14. Sato Y.: Japanese studies on deterioration of ballasted track. Vehicle system dynamics, 24(sup1), 197-208.(1995).

15. Ionescu D.: Evaluation of the engineering behaviour of railway ballast., Ph.D thesis, University of Wollongong. Faculty of Engineering, University of Wollongong. http://ro.uow.edu.au/theses/421 (2004).

16. Gurin N., Sab K. and Moucheront P.: Identification exprimentale d'une loi de tassement du ballast. Canadian geotechnical journal, 36(3), 523-532 (1999).

17. Bodin V.: Comportement du ballast des voies ferrées soumises un chargement vertical et latéral, Ph.D thesis, Ecole Nationale des Ponts et Chaussées (2001).

18. Indraratna B.: and Salim W. Mechanics of ballasted rail tracks: a geotechnical perspective. CRC Press (2005). 
19. Al Shaer A., Duhamel D., Sab K., Forêt G. and Schmitt L.: Experimental settlement and dynamic behavior of a portion of ballasted railway track under high speed trains. Journal of Sound and Vibration, 316(1), 211-233 (2008).

20. Selig E. T. and Waters J. M.: Track geotechnology and substructure management. Thomas Telford (1994).

21. Sadeghi J. and Askarinejad H.: Development of improved railway track degradation models. Structure and infrastructure engineering, 6(6), 675-688 (2010).

22. Kassa E., Andersson C. and Nielsen, J. C.: Simulation of dynamic interaction between train and railway turnout. Vehicle System Dynamics, 44(3), 247-258 (2006).

23. Chaar N. and Berg M.: Simulation of vehicletrack interaction with flexible wheelsets, moving track models and field tests. Vehicle System Dynamics, 44(sup1), 921-931 (2006).

24. Sun Y. Q., Cole C., Spiryagin M. and Dhanasekar, M.: Vertical dynamic interaction of trains and rail steel bridges. Electronic Journal of Structural Engineering, 13(1), 88-97 (2013).

25. Paixão A., Fortunato E. and Calçada, R.: Transition zones to railway bridges: track measurements and numerical modelling. Engineering structures, 80, 435-443 (2014).

26. Alves Ribeiro C., Paixão A., Fortunato E. and Calçada, R.: Under sleeper pads in transition zones at railway underpasses: numerical modelling and experimental validation. Structure and Infrastructure Engineering, 11(11), 1432-1449 (2015).

27. Nguyen K., Goicolea J. M. and Gabaldón F.: Comparison of dynamic effects of high-speed traffic load on ballasted track using a simplified two-dimensional and full three-dimensional model. Proceedings of the Institution of Mechanical Engineers, Part F: Journal of Rail and Rapid Transit, 228(2), 128-142 (2014).

28. Rocha J. M., Henriques A. A. and Calçada, R.: Probabilistic safety assessment of a short span high-speed railway bridge. Engineering Structures, 71, 99-111 (2014).

29. Neves S. G. M., Azevedo A. F. M. and Calçada, R.: A direct method for analyzing the vertical vehiclestructure interaction. Engineering Structures, 34, 414-420 (2012).

30. Neves S. G. M., Montenegro P. A., Azevedo A. F. M., and Calçada, R.: A direct method for analyzing the nonlinear vehiclestructure interaction. Engineering Structures, 69, 83-89 (2014).

31. Montenegro P. A., Neves S. G. M., Calçada R., Tanabe M. and Sogabe, M.: Wheelrail contact formulation for analyzing the lateral trainstructure dynamic interaction. Computers \& Structures, 152, 200-214 (2015).

32. Nguyen K., Villalmanzo D. I., Goicolea J. M. and Gabaldón F.: A computational procedure for prediction of ballasted track profile degradation under railway traffic loading. Proceedings of the Institution of Mechanical Engineers, Part F: Journal of Rail and Rapid Transit, 230(8), 1812-1827 (2016).

33. Li X., Nielsen J. C. and Pålsson B. A.: Simulation of track settlement in railway turnouts. Vehicle System Dynamics, 52(sup1), 421-439 (2014).

34. Kouroussis G., Florentin J. and Verlinden O.: Ground vibrations induced by InterCity/InterRegion trains: a numerical prediction based on the multibody/finite element modeling approach. Journal of Vibration and Control, 22(20), 4192-4210 (2016).

35. Paixão A., Fortunato E. and Calçada, R.: A numerical study on the influence of backfill settlements in the train/track interaction at transition zones to railway bridges. Proceedings of the Institution of Mechanical Engineers, Part F: Journal of Rail and Rapid Transit, 230(3), 866-878 (2016).

36. Iwnick S.: Manchester benchmarks for rail vehicle simulation. Vehicle System Dynamics, 30(3-4), 295-313 (1998).

37. De Man A. P.: Dynatrack: A survey of dynamic railway track properties and their quality (2002).

38. Ewins, D.: Modal testing: Theory, Practice and Application (2nd ed.) Research Studies Press Ltd (2002).

39. Zhai W. M., Wang K. Y. and Lin J. H.: Modelling and experiment of railway ballast vibrations. Journal of sound and vibration, 270(4), 673-683 (2004).

40. Mauer L.: An interactive track-train dynamic model for calculation of track error growth. Vehicle System Dynamics, 24(sup1), 209-221 (1995). 